\title{
The trust as a social capital of civil society in contemporary Russia
}

\author{
Svetlana Maximova ${ }^{1}$, Oksana Noyanzina $^{1, *}$, Daria Omelchenko $^{1}$, and Margarita \\ Maximova $^{1}$ \\ ${ }^{1}$ Altai State University, 656049, Lenin ave., 61, Barnaul, Russia
}

\begin{abstract}
Sociological analysis of indexes of institutional trust and indexes of development of civil society (structured interview, $n=2400$, age of participants 18-70 years in six regions of Russia revealed the condition, problems and tendencies of development of the trust in regions, different by social-economic status. The generalized trust of Russian citizens corresponds to average level and less important than trust to surroundings and readiness to help to the people. We note in particular high level of the trust of Russians and potential cooperation with noncommercial organizations. During the research we revealed a number of factors influencing all types of the trust - generalized one, trust to the institutes of civil society - gender (women more often demonstrated trust, than men), type of place of residence (level of trust higher among rural inhabitants), material condition (rich respondents gave significantly higher values in all types of trust). Representations about importance of civic selforganization, sense of belonging to national, regional and local communities and sense of responsibility are positive characteristics of development of civil society. However, the level of civic activity is not so high $(45 \%)$ and often reduces to one-time charity actions or membership in professional or local territorial unions. Values of indexes, connected with levels of the trust and civic activity considerably differ in different in social and economic status Russian regions.
\end{abstract}

\section{Introduction}

The trust is one of key elements of a social capital of the civil society. In a sense, we are talking about specific culture of the trust, typical to the civil society. In Russia, reasons, caused the significance of trust in contemporary conditions, are the most relevant because of historical trajectories of the Russian state development. Only for the last century, the Russian Federation faced with several political regimes. Hence, the population addressed own hopes, beliefs, and trusted own destinies to each of them. These processes greatly depend on external global processes and internal factors, determining characteristics of relationship of trust at all levels of social system, and, finally, on peculiarities of mentality and national character, other social-cultural determinants of Russian society.

\footnotetext{
* Corresponding author: noe @ list.ru
} 
The level of trust or distrust may be treated as an indicator of public feelings, a "thermometer" of social health and effectiveness of social system as a whole [1-3]. Objective laws and stable patterns of trust behavior in different historical periods and different societies allow to speak about the national cultures of trust, representing a culturally encouraged trustful orientation towards some society, regime, organizations and institutions, independent of personal disposition, rational calculations or other logical grounds [4-6]. The trust is conceptualized as a core element of social capital, maintaining social integrity, playing significant role in fostering group identity, strengthening community spirits and cooperation among citizens, stimulating their self-organization [7-9, $3]$ ). The role of trust in the society is so great that it engenders many metaphors, highlighting its immanent character and relational functions. P. Sztompka [10] defines trust as: 'a bet about the future contingent actions of others'. For Kenneth Arrow [11] trust was 'an important lubricant of a social system'. Manifested in every day practices, the trust underlies value orientations and attitudes, related to social activity, solidarity, tolerance and responsibility.

Meanwhile, in spite of endeavors of Russian powers to support civil institutions by targeted governmental, presidential or regional grant and subvention programs and apparent upsurge of grassroots social patriotically oriented movements, the world-wide and national analytical reports show that the activity and productivity of civil society in Russia remains very restricted (CIVICUS report 2015; CSO Sustainability Index for Central and Eastern Europe and Eurasia 2015; Report of Civic Chamber of the Russian Federation about the state of civil society in 2015). Experts note that the level of trust remains the weak component of social capital of Russian society [12-14]. Hence, the work on enhancement of generalized and institutional trust of citizens would benefit not only public governance system but also civil society organizations in Russia [15-16]. The study of interrelations between depersonalized - general, in-group and institutional trust and the development of civic participation may help to reveal problems existing in different regions and find out possible solutions.

\section{Methods}

The multiplicity of definitions of trust, due on the one hand to the objective multidimensionality and complexity of the concept, and to the theoretical and methodological disunity of researchers focusing on the trust, on the other, allows to consider it as expectation, attitude, state, relation, process of social exchange and communication, personal and social feeling, a form of social solidarity, social competence and so on $[5,17]$. In the general, synthetized sense, the trust is treated as a mental state of individual, conscious of his/her vulnerability or dependence and expecting from 'others' (that may be a concrete person, member of a group or society as a whole), that they will behave predictably, according to accepted rules and norms [18-19].

Depending on who or what is trusted two type of trust are commonly distinguished: interpersonal or horizontal trust, pointed at concrete individuals - partners of interactions in definite social situation, and depersonified trust, going beyond the direct interaction, personal experience and assessment of the credibility of counterparty. This depersonified trust may take the form of generalized trust, disregarding moral qualities and past experience of individuals, or particularized trust, manifested in close relations between members of non-formal groups (relatives, representatives of one ethnic group, professionals etc.), or trust towards organizations and institutions as the most abstract social structures, represented by systems of regulations, norms, rules or roles [20-21]. Hence, depersonified trust may be horizontal or vertical if we are talking about macro-level social objects. It is 
exactly the depersonified trust, which is in the focus of our research, especially its relation with civicness and civic attitudes of people, living in different regions of Russia.

Our research was focused on the study of depersonalized (depersonified) types of trust in six borderland territories of Russia. The analysis about number of indexes was based on the data, collected for the sociological research (multistage stratified sample, $n=2400$, respondents' age from 18 to 70 years) fulfilled in 2015. The research covered six regions of the Russian Federation: the Altai, the Jewish Autonomous, the Trans-Baikal, the Kemerovo, the Omsk and the Orenburg regions.

The choice of regions based on the following:

First of all, highly uneven distribution of institutes of civil society between Russian regions. Thus, in the research by the Public Chamber in 2015 was realized analysis of the "third sector" and revealed dependencies between the number of inhabitants in federal districts and their social-economic development and number of non-governmental organizations. As a result, all Federation subjects and districts were classified.

Second, all subjects of the Federation are differ by various regional problems in social and economic development and influencing factors. Accordingly, we used the typology of subjects by the Independent Institute of Social Policy to choose regions for the res earch.

Third, the choice caused by border position of observed regions. Geography, history of settling and characteristics of ethnic composition influenced regional ethnic-cultural processes, and, in result, peculiarities of interpersonal and institutional trust and Formation of the civil society institutes.

As estimation instruments, we used classic scales of trust and question batteries, usually used in international research projects, such as the General Social Survey and the World Values Survey, and Russian national surveys by the VCIOM and Levada-Center. Some scales were modified to get differentiated and close to quantitative evaluations. Primary descriptive analysis supplemented by IRT graded response models were used to calculate integral indexes of generalized, informal and institutional trust, and estimate psychometric quality of obtained scale and its elements.

For the generalized trust evaluation, a classical question "Generally speaking, would you say that most people can be trusted or that you need to be very careful in dealing with people?" was used, but instead of two possible answers, it was assessed by 10 -point scale. The second question clarified the first one and specified trust to the surroundings. Meanwhile, we did not indicate, which people are they (there are a lot of unfamiliar faces around each of us), so the question was a reduction of generalized trust to social area, limited by respondent's place of residence. The third question was about readiness to provide mutual assistance in social surrounding of an individual as indicator about potential to interact and cooperate, representing immanent characteristic of the generalized trust. Despite no direct connection with respondent, only his or her typical environment, the mechanism of projection effected the respondent and transferred expectations and predispositions to the behavior of hypothetical others.

\section{Results}

According to the descriptive analysis, the level of generalized trust in Russian borderlands was rather moderate from three to six points; the mean value was 4.57 points, median value - 5 points. Respondent's environment estimated as credible, reliable and safe, hence. Estimations about mutual assistance were intermediate between evaluation of the generalized trust and trust to environment (Fig. 1). 

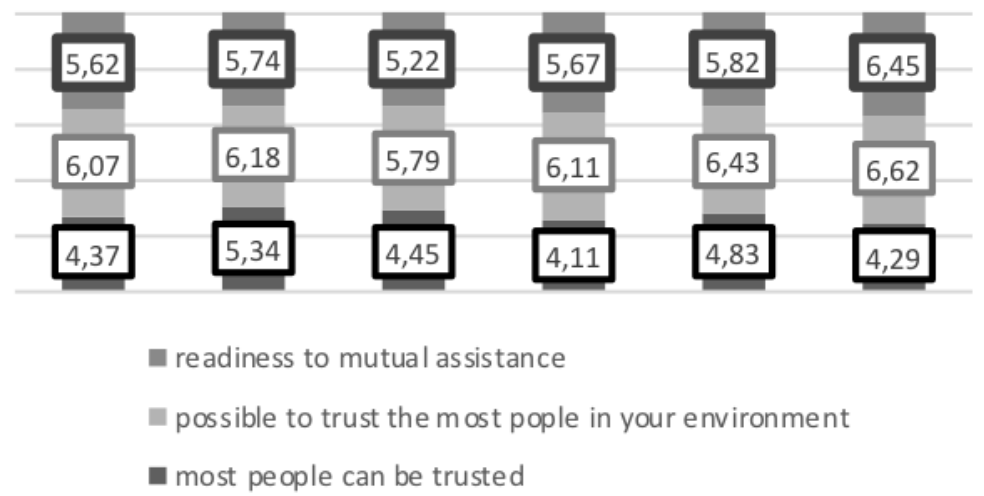

Fig. 1. Generalized trust in Russian borderlands, means.

At the next stage, we revealed significant social-demographic and social-cultural factors, influencing the generalized trust. Each three variables demonstrated significant differences between groups with different level of education and type of settlement. Rural inhabitants demonstrated high level of the generalized trust than urban residents.

An ambivalent effect was found in relation to the impact of educational attainment: generalized trust were positively associated with the growth of educational capital. Whereas, respondents with higher social status had higher level of generalized trust. General differences marked, from the one hand, between groups of pensioners and employees, and with high flags of leaders, from the other. Age factor was latent in distribution of respondents between status groups (implicitly, students and pupils are younger than pensioners are), and did not have independent effect. Looks like social status, we revealed similar interdependence with income level and proved our thesis about higher level of generalized trust of wealthy successful respondents, occupying higher steps at social stairs and having huge opportunities of control and prognosis, opportunities of choice of decisions. We fixed many differences in answers between financially secured and rich respondents, and other categories of respondents.

In addition to generalized trust, self-evaluation of financial opportunities influenced altruistic tendencies. However, the more considerable differences were found between evaluations of deprived respondents, who are poor and very poor, and evaluation of other groups. Thus, the common attitude to trust associated with high social status, but its estimation testified about the evident lack of belief in high social status among needy citizens (table 1).

Table 1. Social-demographic and social-cultural factors, influencing the generalized trust $*-\mathrm{p}<$ $0,05, * *-\mathrm{p}<0,0$.

\begin{tabular}{|c|c|c|c|c|}
\hline \multicolumn{2}{|c|}{ factor } & $\begin{array}{c}\text { generalized } \\
\text { trust }\end{array}$ & $\begin{array}{c}\text { trust to } \\
\text { environment }\end{array}$ & mutual assistance \\
\hline \multirow{2}{*}{ residence } & city & $4,45^{* *}$ & $6,13^{*}$ & $5,68^{*}$ \\
\cline { 2 - 5 } & village & $4,81^{* *}$ & $6,36^{*}$ & $5,92^{*}$ \\
\hline \multirow{2}{*}{ sex } & men & 4,52 & 6,1 & $5,61^{*}$ \\
\cline { 2 - 5 } & women & 4,61 & 6,29 & $5,87^{*}$ \\
\hline \multirow{2}{*}{ education } & higher & $4,84^{* *}$ & $6,42^{* *}$ & $6,05^{* *}$ \\
\cline { 2 - 5 } & average & $4,42^{* *}$ & $6,09^{* *}$ & $5,6^{* *}$ \\
\hline \multirow{3}{*}{ status } & pupils & $4,85^{* *}$ & 7 & 6,19 \\
\cline { 2 - 5 } & employees & $4,48^{* *}$ & 6,29 & 5,83 \\
\cline { 2 - 5 } & unemployed & $4,53^{* *}$ & 5,97 & 5,49 \\
\hline
\end{tabular}




\begin{tabular}{|c|c|c|c|c|}
\hline \multirow{4}{*}{} & pensioners & $4,37 * *$ & 6 & 5,58 \\
\cline { 2 - 5 } & leaders & $4,97^{* *}$ & 6,17 & 5,88 \\
\cline { 2 - 5 } & students & $4,67 * *$ & 6,38 & 5,69 \\
\hline \multirow{3}{*}{$\begin{array}{c}\text { financial } \\
\text { condition }\end{array}$} & very poor & $4,15^{* *}$ & 5,58 & $5,33^{*}$ \\
\cline { 2 - 5 } self-evaluation) & poor & $4,41^{* *}$ & 6,02 & $5,37 *$ \\
\cline { 2 - 5 } & average & $4,51^{* *}$ & 6,22 & $5,79 *$ \\
\cline { 2 - 5 } & rather rich & $4,94^{* *}$ & 6,32 & $5,99^{*}$ \\
\cline { 2 - 5 } & rich & $4,96^{* *}$ & 6,38 & $6,04^{*}$ \\
\hline
\end{tabular}

Coming from the abovementioned differences, we may conclude about generalized trust, describing not only individuals of society in whole, but also certain social groups and stratums. Social inequality and stratification, differences in the way of life, attitudes and beliefs lead to uneven dispersion to trust. Meanwhile, some groups have higher level of trust, lager volume of social capital, but some - have lower trust, which decreases the level of social and economic activity, becomes factor of disintegration and exclusion from the system of social networks and relations, formation of isolated enclaves. For example, as a villages or city districts with dominantly poor inhabitants.

On the base of logistic regression models in each region, we explored the association between trust and social-demographic and social-cultural factors. In a result of the IRTmodelling, the scale (index) of generalized interpersonal trust was dependent variable and social-demographic demographic characteristics as independent predictors.

The key factors, effecting the level of generalized trust in all regions were level of education, sex, place of residence, social status, and self-assessment of material position.

Evaluations of generalized trust significantly vary in Russian borderlands. Nationality is specific factor in the Altai region, and religiousness in the Kemerovo oblast (table 2).

Table 2. Generalized linear models of generalized trust in regions, standardized coefficients, * $\mathrm{p}<0,05, * *-\mathrm{p}<0,01$.

\begin{tabular}{|c|c|c|c|c|c|c|c|}
\hline Factors $\backslash$ Region & Altai & Jewish & $\begin{array}{c}\text { TransBaika } \\
1\end{array}$ & Kemerovo & Omsk & Orenburg & Total \\
\hline $\begin{array}{c}\text { Education } \\
\text { (highest) }\end{array}$ & $0,25^{* *}$ & 0,19 & $-0,05$ & 0,11 & 0,04 & $0,28^{*}$ & $0,15^{*}$ \\
\hline Sex (women) & $-0,03$ & $0,27^{*}$ & 0,05 & 0,05 & 0,04 & 0,10 & $0,08^{*}$ \\
\hline $\begin{array}{c}\text { Residence } \\
\text { (village) }\end{array}$ & $-0,02$ & $0,42^{* *}$ & $-0,12$ & 0,01 & $0,28^{*}$ & 0,05 & $0,13^{*}$ \\
\hline $\begin{array}{c}\text { Nationality } \\
\text { (Russians) }\end{array}$ & 0,22 & 0,18 & $-0,18$ & 0,14 & 0,11 & 0,08 & 0,05 \\
\hline $\begin{array}{c}\text { Religion } \\
\text { (believers) }\end{array}$ & 0,06 & 0,02 & $-0,05$ & $0,26^{*}$ & 0,05 & 0,16 & 0,06 \\
\hline Status (pupils) & $-0,03$ & 0,70 & 0,17 & 0,42 & $-0,08$ & 0,42 & $0,35^{*}$ \\
\hline $\begin{array}{c}\text { Status } \\
\text { (employees) }\end{array}$ & 0,06 & 0,12 & 0,09 & 0,17 & $-0,04$ & $-0,03$ & 0,07 \\
\hline $\begin{array}{c}\text { Status } \\
\text { (pensioners) }\end{array}$ & 0,13 & $-0,09$ & $-0,02$ & 0,21 & $-0,07$ & $-0,21$ & $-0,01$ \\
\hline Status (leaders) & $0,29^{*}$ & $-0,03$ & 0,18 & 0,32 & 0,27 & $-0,04$ & 0,12 \\
\hline Status (students) & 0,01 & 0,12 & 0,30 & $1,05^{* *}$ & 0,04 & $-0,12$ & 0,19 \\
\hline Finance s & 0,10 & 0,08 & $0,19^{*}$ & $-0,01$ & 0,06 & $-0,03$ & $0,06^{*}$ \\
\hline
\end{tabular}

The obtained data hand an important part, connected with trust to the activity of various civil institutes. 5-point Likert scales assessed all items, related to institutional trust. Particular indexes of trust calculated basing on descriptive statistics.

Respondents feel considerable trust to the Russian Orthodox Church and public organizations, consumer protection societies and charity organizations. Human rights and ethnic-cultural organizations occupied rather low positions in the overall rating positive 
indexes of trust to social institutions. Other public institutes, such as mass media, other religious institutes, ethnic diaspora, local authorities and political parties had negative trust indexes.

From the one and, respondents highly trusted to non-governmental organizations and potentially ready to cooperate, but, from the other hand, we revealed evident discrediting of confessional diversity beyond dominating Orthodoxy. Diasporas seem suspicious, and low trust level to political parties testifies about crisis in Russian institutional policy (Fig. 2).

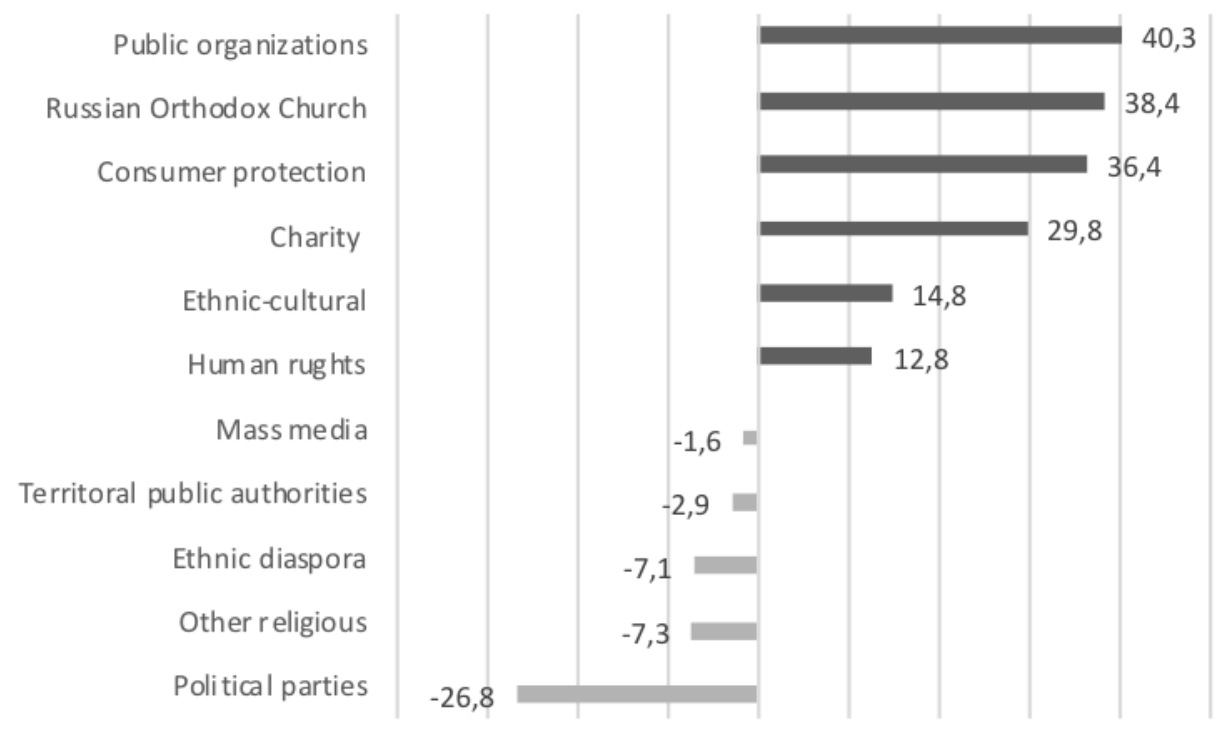

Fig. 2. Indexes of trust to public institutions.

The research has revealed factors, influencing trust to social institutes in different social groups. Over half of respondents in all six regions thinking about disunity between people in Russia (54.2\%). Residents of the Jewish autonomous region often evaluate social relations as consensus and cohesion (38.7\%), the most negative are respondents in the Transbaikal and the Kemerovo regions (63.1\%), (62.9\%).

In Russia, the power factor is a strong mean of disintegration of society, and general tendency is extremely low value of social dialogue between "powerful" and "powerless". Only $12 \%$ of respondents are positive in evaluating perspective of mutual understanding and cooperation between ordinary people and whose, who has authority. Over the fourth of respondents $(25.3 \%)$ are sure in the impossibility of dialogue between stratums with different authority access.

Analysis of institution conditions of development of civil society based on evaluation of 25 indexes, assessed by 10-point scale. Ranking of the mean values revealed conditions, important for the development of civil society (table 3). Tolerance to other ethnos and religions, persons of different confessions rather high expressed, free and responsible mass media objectively talk about social problems, executives effectively realize service in culture, education and health care systems, federal center and regions rationally divided in responsibilities. However, we fixed inefficiency of anti-corruption laws and weak professional unions. 
Table 3. Institutional conditions of civil society development (top- 5 expressed and 5 lessexpressed indexes).

\begin{tabular}{|l|c|c|c|}
\hline & $\mathrm{M}$ & $\mathrm{m}$ & $\mathrm{Mo}$ \\
\hline Tolerance to ethnic aliens & 6,16 & 0,049 & 5 \\
\hline Tolerance to confession, persons of other religions & 6,1 & 0,05 & 5 \\
\hline Free and responsible mass media, objective about social problems & 5,06 & 0,046 & 5 \\
\hline $\begin{array}{l}\text { Governmental is effective cultural, education and health care } \\
\text { services }\end{array}$ & 5,02 & 0,048 & 5 \\
\hline $\begin{array}{l}\text { Rational division of competence between federal center and } \\
\text { regions }\end{array}$ & 5,02 & 0,046 & 5 \\
\hline$\ldots$ & & & \\
\hline Regional government is effective in conflict resolution & 4,42 & 0,048 & 5 \\
\hline Effective system of regional management & 4,4 & 0,05 & 5 \\
\hline Economy provides equal rights and guarantees to needy people & 4,38 & 0,045 & 5 \\
\hline Professional unions are fighting for employer's interests & 4,29 & 0,05 & 1 \\
\hline Anti-corruption lows are strong and actual & 4,03 & 0,049 & 1 \\
\hline
\end{tabular}

We identified the average level of generalized trust of contemporary Russians. From the one hand, people highly trusted and were ready to cooperate with public organizations, and had low civic and public activity, from the other.

Over the half of respondents in borderlands (68.2\%) do not cooperate with nongovernmental organizations. Urban citizens more often engaged in work of noncommercial sector, than rural. The most popular among population are the following democratic institutes: local authorities, local initiative neighborhood groups. Urban citizens more often engaged in activities of charity and youth organizations, political parties, human rights and social service organizations. Rural residents often engaged in ecology or environmental organizations, and activity of territorial public administrations.

Interaction between evaluations of different categories of respondents let to specify three factors, determining favorable or unfavorable evaluations of the civil society in Russia. The first describes actions and nature of various social institutes, necessary for stable development of civil society. The second one characterizes conditions of social justice for formation and development of civil society. The third pace, in the factor structure occupy base values of tolerance, tolerance to the "alien".

\section{Conclusions}

Generalized trust of respondents in Russian borderlands corresponds the average level; lower than the interpersonal trust and readiness for mutual assistance. The highest disproportions of generalized trust fixed between the Orenburg with rather high trust level and the Trans Baikal region with crisis of interpersonal trust.

The trust to non-formal groups acts as an intermediate point between interpersonal and depersonified as well as between interpersonal and institutional form of trust, ensuring basic need in social contacts and moral support from people with shared identity. This kind of trust plays a dual role in the development of social capital and civil society: in one way, it contributes to the development of horizontal relations, based on mutual trust and shared common values, so important for civic initiatives. The Trans Baikal region is specified by lowest indexes of informal trust in relation to other explored regions.

Population has high level of trust and readiness to cooperate to noncommercial organizations: the highest in the Orenburg oblast, the lowest - in the Omsk region.

The hierarchy of levels of trust towards State institutions evidently displayed a trend of centralization: the higher was the level of governance, the higher were assessments of trust. The highest degrees of trust were traditionally placed in the President and in the Russian 
army, whose authority is almost indisputable and deeply rooted in the conscience at the level of archetypes.

Sex, place of living and material condition influenced all type of the trust: women, rural residents and rich people have higher level of trust. Nationality positively effected the level of institutional and social trust, religion positively associated with state and social institutes.

Age factor showed intergeneration and worldview gaps in the world perception. The young people more tolerant to public institutes of contemporary societies, in the contrary, the elder generation demonstrates commitment to patriarchal values and trust traditions.

The most vulnerable categories of populations from the point of view of lack of different types of trust were those who had been excluded socially and economically unemployed and living under the poverty level.

Paper is prepared in the frameworks of the Russian Fund of Fundamental Researches Grant № 17-33-00049 'Institutional and interpersonal trust as a social capital of development of civil society in contemporary Russia' (2017 - 2019).

\section{References}

1. E. M. Uslaner, Generating social capital, 171-190 (2003)

2. J. Delhey, K. Newton, European Sociological Review, 21(4), 311-327 (2005)

3. N. Letki, Political Behavior, 28(4), 305-325 (2006)

4. K. Arrow, The Limits of Organization (1974)

5. P. Sztompka, European Journal of Social Theory, 1(1), 19-32 (1998)

6. A. B. Seligman, Trust and civil society, 12-30 (2000)

7. R. Inglehart, C. Welzel, Modernization, cultural change, and democracy: The human development sequence (2005)

8. J. Nahapiet, S. Ghoshal, Academy of management review, 23, 2, 242-266 (1998)

9. J. S. Coleman, Knowledge and Social Capital, 17-41 (2000)

10. R. D. Putnam, Culture and Politics, 223-234 (2000)

11. P. Sztompka, Trust: A sociological theory (2008)

12. K. Arrow, The Limits of Organization (1974)

13. R. Rose, Getting things done in an anti-modern society: Social capital networks in Russia, 6 (1998)

14. M. Woolcock, D. Narayan, The World Bank research observer, 15(2), 225-249 (2000)

15. J. L. Twigg, K. Schecter, Social capital and social cohesion in post-soviet Russia (2003)

16. I. Mersiyanova, E. Pakhomova, Public administration issues, 4, 98-119 (2012)

17. F. Fukuyama, Trust: The social virtues and the creation of prosperity (1995)

18. J. A. Colquitt, B. A. Scott, J. A. Le Pine, Journal of applied psychology, 92, 4, 909912 (2007)

19. Civil Society Organization (CSO), Sustainability Index for Central and Eastern Europe and Eurasia (2015)

20. Report about the state of civil society in the Russian Federation in 2015 (Moscow, 2016)

21. A. M. Evans, J. I. Krueger, Social and Personality Psychology Compass, 3, 6, 10031017 (2009) 
22. R. D. Putnam, K. A. Goss, Democracies in Flux: The Evolution of Social Capital in Contemporary Society, 3-21 (2002)

23. D. Stolle, Austrian Journal of Political Science, 31, 4, 397-412 (2002) 